\title{
Introduction: Moments of the Theologico-Political
}

\begin{abstract}
mo•ment
Noun. Pronunciation: I'mō-məntl. Etymology: Middle English, from Middle French, from Latin momentum, movement, particle sufficient to turn the scales, moment, from movere, to move. Date: Fourteenth century. 1 a: a minute portion or point of time: INSTANT b: a comparatively brief period of time 2 a: present time <at the moment she is working on a novel> b: a time of excellence or conspicuousness $<$ he has his moments> 3 : importance in influence or effect <a matter of great moment> 4 obsolete: a cause or motive of action $5:$ a stage in historical or logical development 6 a: tendency or measure of tendency to produce motion especially about a point or axis b: the product of quantity (as a force) and the distance to a particular axis or point 7 a: the mean of the nth powers of the deviations of the observed values in a set of statistical data from a fixed value b: the expected value of a power of the deviation of a random variable from a fixed value synonym: see IMPORTANCE -Merriam-Webster's Dictionary
\end{abstract}

We must now decide what incidents seem dreadful or rather pitiable. Such must necessarily be the actions of friends to each other or of enemies, echthroi, or of people that are neither. Now if an enemy does it to an enemy, there is nothing pitiable either in the deed or in the intention, except so far as the actual calamity goes.

-Aristotle, Poetics

In this book, I am engaging how the enemy becomes enemy, the history of the enemy that is inscribed within and between the polarized identities of Jew and Arab. If it constitutes a history, it is one that is longer than a colonial one, although colonial dimensions - the implication, indeed, the founding and continuing role of British colonialism and American imperialism, to mention only two prominent actors, in the creation and the continuation of the "Middle East conflict" - are perhaps better known and better studied, if not necessarily better understood. But The Jew, the Arab: $A$ History of the Enemy is also less than a history-less a history, that is, than a preliminary account of why that history has not been written. 
Beyond a horridly all too familiar and inescapable "cycle of violence," what is it that maintains the distance and kindles the enmity between the Arab and the Jew? What purposes are served by, what are the reasons for, the naturalization of this distance, the naturalization of the opposition, of the enmity between Arab and Jew, one that, as prominent narratives would have us believe, goes back to ancient biblical times, the ineluctable legacy of "the Middle East," a region and a land eternally ravaged by war and conflict? How did the ostensible markers of Arab (an "ethnic" marker) and Jew (a "religious" one) come to inscribe themselves so forcefully on modern discourses of the most varied kind-political, religious, cultural, and so forth-even when accompanying distinct or even opposed political agendas, caveats and sophisticated critiques and debunkings?!

Law is perhaps the single most important apparatus by way of which, in the course of the nineteenth and twentieth centuries, the colonial state ruled over its populations. As Mahmood Mamdani puts it, "one single claim defined a shared civilizational project: whether rulers or ruled, Westerners or non-Westerners, all those subjects to the power of the state would be governed through imported Western law." "Within this legal system, the state deploys "repressive and productive mechanisms" that participate in formulating "the new as that which has always been."3 One of these mechanisms, and the basis for distinguishing and indeed discriminating between colonizer and colonized, was race. Such discrimination, however, was not enough, and further distinctions were introduced, sometimes even prior to the official establishment of Western law, prior to the full institution of colonial rule. The temporality of these distinctions is thus less important than the structures they put in place. At one level, then, one finds "a racial separation in civil law between natives and nonnatives," between colonizers and colonized. At another level, however, natives themselves are "divided . . . into separate groups and governed each through a different set of 'customary' laws."

In addition to race, law thus constituted another, distinct categoryethnicity. "The very category 'native' was legally dismantled as different groups of natives were set apart on the basis of ethnicity. From being only a cultural community, the ethnic group was turned into a political community." By invoking "local customs," a sphere was created within (Western) law that was outside the law, within the law, yet outside of its jurisdiction, a sphere governed by distinct cultural and political imperatives. "Within a single legal order" there emerged distinct ethnic differences, that 
is to say, naturalized political differences. "The language of the law tried to naturalize political differences in the colony by mapping these along a civilizational ladder. As the litmus of a civilizational test, the law separated the minority of civilized from the majority of those yet-to-be-civilized, incorporating the minority into a regime of rights while excluding the majority from the same regime." ${ }^{4}$

What is important to consider, therefore, is the history whereby the distinction between race and ethnicity is here primarily a legal distinction by means of which a population is both included (ruled by Western law) and excluded (deemed to be exterior to the law by the law) and falling under a different set of laws named "customary." The colonial state and Western law produced political differences within the colonized, but it also naturalized these political differences as cultural, and indeed ethnic. Within one legal system, within one colonized population, there emerged internal differences between ethnicity and race, between majority and minority, between indigenous and nonindigenous (26-27).

As Mamdani accounts for the regime of divisions that was established in Africa, he explains that the racialized minorities that were lifted above the majority of the colonized were defined as "subject races." They came to be identified as distinct from the majority of the colonized as nonindigenous and became "virtual citizens." They were

deprived of rights of citizenship, yet considered to have the potential of becoming full citizens. Though colonized, they came to function as junior clerks in the juggernaut that was the civilizing mission. Without being part of the colonial rulers, they came to be integrated into the machinery of colonial rule, as agents, whether in the state apparatus or in the marketplace. As such they came to be seen as both instruments and beneficiaries of colonialism, however coerced the instrumentality and petty the benefits. Though part of the colonized population, the subject races received preferential treatment under the law. In contrast, subject ethnicities were set apart and literally sat upon, legally. (27)

In Africa, Mamdani explains, the subject races were many. The list extends to the Asians of East Africa, the Indians and "Coloured" of South Africa, the Arabs of Zanzibar, and, of course, to the Tutsi of Rwanda and Burundi (28). The terrible history of the political divisions that, naturalized by colonial rule, sedimented as cultural distinctions that were later to lead to what has been called "ethnic violence" in Rwanda, is what Mamdani describes and, more importantly, explains and interrogates. Colonial rule produced political identities, identities that it proceeded to naturalize. In a process 
that has remained for the most part invisible, "the Tutsi were constructed by colonial ideology as well as law as nonindigenous Hamites," a distinct "race . . both civilizing and alien" $(28,89)$.

The so-called Hamitic hypothesis served as part of an extended ideological apparatus meant to "turn the Tutsi, the 'born rulers' of Rwanda, into an elite 'capable of understanding and implementing progress,' and thus functioning as auxiliaries to both the missionaries and the colonial administration." A school system was created "that could act as a womb of racial ideology." Thus, the Tutsi "were given a 'superior' education, taught in French in a separate stream. The assimilationist education prepared them for administrative positions in government and testified to their preparation for citizenship, even if at the lowest orders" (90). Much like the Jews of Algeria - who, uniquely, were granted French citizenship in $1870,{ }^{5}$ thus becoming the embodiment of a distantly shimmering promise extended to Jews of the entire Arab world, a promise that was dutifully maintained, if not quite realized, by the Alliance Israélite Universelle-the Tutsi became nonnative outsiders, a political minority that did not belong to the native community. They became internal enemies.

In order to understand the Rwanda genocide, "whereby it became possible not only to set a group apart as an enemy, but also to exterminate it with an easy conscience" (I3), Mamdani proposes to attend to the ways in which both race and ethnicity are legal and political inventions, the sedimented result of a complex legal process. He proposes to "understand the dynamic that polarizes political identities" (23), identities that are "legally enforced and institutionally reproduced" (I5) and that had not existed (not in any comparable way) prior to colonial rule. Although distinctions were and are always operative within any given cultural system, they could always fluctuate and change, "shade into one another, with plenty of middle ground to nurture hybridity and ambiguity" (23). Yet, with the kind of polarization that is produced under colonial rule, "there is no middle ground, no continuum, between polarized identities. Polarized identities give rise to a kind of political difference where you must be either one or the other. You cannot partake of both. The difference becomes binary, not simply in law but in political life. It sustains no ambiguity" (23).

Thanks to Mamdani's magisterial demonstration, the polarization of Hutu and Tutsi along political, racial, and ethnic lines is now well known. But Mamdani suggestively opens a different area of reflection when he asks about the possible futures that are facing Rwanda after the genocide. In- 
troducing a somewhat enigmatic parallel, Mamdani raises the following questions: "Will Rwanda follow the example of Israel, and create a separate community of Tutsi, alongside another of Hutu? ${ }^{6}$ Will it follow the example of Zanzibar and merge in a larger union with the tendency to dissolve bipolar political identities . . . in a wider arena with multiple political identities? Or will it charter a third course . . by trying to forge a political identity that transcends Hutu and Tutsi?" (265) Despite the enormous difficulties involved with generalizations and, most particularly, with comparisons such as these (and suspending, for now, the violent processes whereby European Jews became colonizing settlers, as well as the continuities between anti-Semitism and Zionism and the identifications and complicities that link Europe's colonial history to the colonization of Palestinian Arabs by European Jews), they pose troubling yet necessary questions. Who, in Israel and Palestine, are the Hutu, and who the Tutsi? And what are the historical, legal, religious, and political processes that have come to naturalize the Jew and the Arab as polarized identities? Though he does not take the term as a dominant marker of his inquiry, Mamdani does make clear that any answer to these queries has to engage the question-and the history - of the enemy: "Before you can try and eliminate an enemy," Mamdani writes, "you must first define that enemy. The definition of the political self and the political other has varied throughout history. The history of that variation is the history of political identities, be these religious, national, racial or otherwise" (9). The question of the enemy emerges and recurs here as the history of political identities, as the history, perhaps, of the political. How, for example, did it become possible in this particular case "not only to set a group apart as an enemy, but also to exterminate it with an easy conscience" ( $(\mathrm{r} 3)$ ? And how did the killings in Rwanda "remain directed in the main at those identified as the political enemy, not the class enemy" (194)? What were the conditions that brought about a "truly disturbing aspect of the genocide," namely, that "the definition of the enemy appeared credible to many ordinary Hutu" (202)? What is the history that led to the emergence of an "internal enemy," an enemy who was quickly turned into an outsider to be fought with, expelled, and later exterminated? And how did the sedimentation of political identities produce such chillingly effective results? Much like the Hutu Presidential Guard, the Hutu moved "from confronting the enemy that seemed to advance relentlessly on the battlefield or on the diplomatic frontier" and "turned around to face the enemy within" (207). Yet that enemy had not simply been there 
to be faced. It had to be found and, indeed, searched for. They turned "away from the enemy on the battlefield ... [and] looked for an enemy within" (215).

Early on in his argument, Mamdani recalls that "Europe 'solved' its political crisis by exporting it to the Middle East" (39). This is undoubtedly true. But what was Europe-what is it still- that it had this particular crisis to export? And what does that have to do with the Jew, the Arab? Most analyses so far have focused on this export of the "Jewish question," considering the choice of Arab Palestine as a contingency of European colonialism or as a result of Zionist aspirations. Other important analyses attend to the transformations of another history, the history of the opposition between "Islam and the West." To put it schematically, the first analyses attend to anti-Semitism, the latter to Orientalism. Without diminishing the accuracy of these accounts or the injustice involved in making Palestinians pay for the guilt of Europe vis-à-vis the Jews, one must nonetheless consider that these accounts entirely take for granted distinct states of enmity (between Jews and Arabs, between Europe and the Arabs, between Europe and the Jews, compounded in this last case by some eternally irreparable guilt) while ignoring the possibility of hidden links and explicit associations between these pairings. ${ }^{7}$ They forego explanation of the historical problem that enmity poses, failing to engage the three "elements" at once (Europe, the Jew, the Arab).

They presuppose, for example, and without interrogating it, the separation of two groupings, "Europe and the Jews" and "Islam and the West" (to quote two celebrated subject headings) and reinscribe the stability of an "idea" of Europe (one that continues to be as fragile today as it ever was, even at its most violent moments of enforced identity), an idea that would exist without necessary relation to the Jew and/or the Arab. These accounts also take for granted the distinction of Arab and Jew as two polarized identities having been constituted independently of each other. There is, of course, no point in denying that such perspectives are quite plausible, even valid and necessary to pursue. They can moreover be complemented, if still insufficiently, by corrective studies that attend to Mediterranean culture or to the three monotheistic religions as a unit of one kind or other. Yet one cannot help but wonder at the absence of any consideration, any sustained analysis, or even any history of "Europe" in its relation to both Jew and Arab.

By suggesting that only the "Jewish question"- and not an "Arab" 
one-has been exported by and out of Europe, one foregoes such account of Europe. Moreover, one naturalizes and separates anti-Semitism and Orientalism in their distinct and anachronistic historical garbs, and, more importantly, one treats both Jew and Arab as simply existing categories that would have, except for few exceptions, not to say aberrant instances ("Medieval Spain," "Bosnia-Herzegovina"), thoroughly and hermetically distinct histories. There is more at stake here than a correction of the historical record on Arabs and Jews vis-à-vis or outside of the "Christian West." (Did they really get along? Could they? Why did/do they hate each other? And why do they hate us? Was it peaceful coexistence? What was their true contribution to philosophy, to science, to civilization? And then what happened? And so forth.) Nor-does this really need to be said?-is it a matter of asserting that this wrestling match is not of two (or three) parties, but of one, that there are no differences or distinctions to be made and maintained. The very framing of the question, and, more importantly, the reflection on its constitutive elements persists in considering either Jew or Arab and their "place" in Europe independently of each other. (If it is us and them, for example, then the com-pearance, not the identity, of both us and them is what continues to be at issue.) Such an approach is neither sufficient to account for the current state of affairs (the so-called "peace efforts" of the Western powers in the Middle East, as well as their "failures") nor does it recognize the ways in which these two political identities- the Jew, the Arab-have been coconstituted by and most importantly with and within Europe. The question that this book attempts to raise, then, is: What is Europe? What is Europe such that it has managed to distinguish itself from both Jew and Arab and to render its role in the distinction, the separation, and the enmity of Jew and Arab invisible-invisible, perhaps most of all to itself? Otherwise put, how has the history of the enemy become an impossible history?

\section{Europe}

The banality, in Hannah Arendt's sense, of yet another division: Europe-so-called "Christian Europe" - divides itself, from the beginning, between an enemy within and an enemy without. "Christianity is coextensive with the West," writes Jean-Luc Nancy, "with a certain process of Westernization that consists in a form of self-reabsorption and self-overcoming." 8 In other words, Christianity as Europe is affected by an internal 
conflict, a conflict that "takes the form of a schizophrenia or an internal division" (II7). It is this Christianity, this Europe, about which Nancy wonders "why our gaze appears always to be turned systematically away from [it] ... almost as if we did not want to look the Christian in the face," and it is this Europe, this Christianity, that Nancy defines as "the very thingthe thing itself - that has to be thought" (II3).

Nancy illuminates Europe's division by undoing its exteriority, attending to the history of its "becoming internal." Thus, Europe's "internal conflict (one that is today becoming internal to Judaism and Christianity, albeit in entirely different ways) has nothing to do with the conflict... between Christianity and Judaism, nor with the conflicts that exist between all great religions." This is why Nancy defines the task as a reflection on an "internal division." As he makes clear, however, this interiority is the result of a history-what Nancy refers to as "the possibility of its becoming"-a becoming-internal of Europe's conflict and the preservation of a certain integrity. "At the heart of Christianity lies a specific type of conflict that is best defined as the conflict between an integrity and its disintegration" (II7). This task of thinking, as Denis Guénoun puts it, "to think Europe in a double manner," has to attend, therefore, to the division of Europe, to its double alterity-if alterity is what is at stake here. This internal division of a space (Europe) between exteriority and interiority is constitutive of Europe, of the "possibility of its becoming," which always deconstitutes itself. ${ }^{9}$

Europe is a name. And the common name that is Europe, Guénon suggests in his striking book Hypothèses sur l'Europe, is constituted as a commonplace, a place in common that is also the site of a division, the site of a separation. Guénoun deploys a logic that, formalized by Jacques Derrida in The Other Heading, is structured by two "axioms." First, Europe rests on a "feeling" that, says Derrida, "we are younger than ever, we Europeans, since a certain Europe does not yet exist. Has it ever existed?"10 And second, "what is proper to a culture is to not be identical to itself" ( $9 / \mathrm{FI} 6)$. What must be retained from this logic of separation and distance-if it is a logic - is that the feeling that is Europe remains at bay, separated from the Europe toward which it is heading, a Europe the existence of which is therefore in doubt, suspended. Europe - that is, also, "we Europeans"-is thus distanced from itself by virtue of a feeling that fails to ascertain the existence of its object. Over against the "idea of Europe," which, for Edmund Husserl, for example, is "a cognitive certitude, apodictably intuitable," 
Derrida's invocation of a feeling asserts that Europe is "not an assured cognitive truth." ${ }^{11}$ Europe's existence is and has been quite uncertain, its identity, like that of any culture, being constituted-as condition of possibility and impossibility - by its nonidentity with itself.

Rodolphe Gasché comments that this nonidentity is itself doubled, is "double in kind."12 First, the identity of a culture-here, Europe-presupposes "an external difference. This is a difference with itself that derives from identity's continual reference to the identity of other cultures over and against whom any self-identity is established. These other cultural identities, as identities of the Other, can simply be different from the one of European culture, but they can also be identities that stand in relation of opposition to European identity." 13 The second necessary condition of any cultural identity is that this identity "must be further divided by an internal difference, a self-difference," which is "the difference of any identity not from the state of non-identity from which it had to be wrenched, but with a 'state' anterior to the difference of identity and non-identity." ${ }^{14}$ As Derrida puts it, "there is no self-relation, no relation to oneself, no identification with oneself, without culture, but a culture of oneself as a culture of the other, a culture of the double genitive and of the difference to oneself. The grammar of the double genitive also signals that a culture never has a single origin. Monogenealogy would always be a mystification in the history of culture." 15

It is between these two violent openings, these two conditions of possibility and impossibility, which one could also somewhat simplistically and quite unfaithfully recast as the distinction between empirical conditions and transcendental ones, that Guénoun situates Europe, the common name and common site that is Europe, which produces and reproduces, as coconstitutive, the distinction and indeed the opposition between the theological and the political. "The theologico-political," writes Guénoun, "is decisively the site of the theologico-political difference." ${ }^{16} \mathrm{He}$ thus attends to the complex history whereby what was never a unity comes to be constituted and reconstituted as the institutionalization of a cut ("the Emperor will not be the bishop, Cesar will not be the Pope," 52), which "simultaneously posits a space and a separation, a separation inscribed in the topical community, as an internal incision without scar" (52), the "mimetic rivalry of Church and Empire" ( 58 ) as well as the desire for and against a "reunification" of the theological with the political (IO8). Guénoun explores the internal difference of each of the terms, insisting, for ex- 
ample, that the theological as well as the religious occur as difference, that is, as internal and external differences whereby "religion is constituted as the difference between religions" (II7).

Simultaneously, Guénoun adds, the political in its internal difference is constituted out of religious division (II7 n. 33). ${ }^{17}$ Guénoun thus links the history of political change in Europe to this particular division, to what he calls the "theologico-political difference." In this history, the nation that begins to emerge with the French Revolution is "the (theologico-political) figure of the inverted kingdom," as well as the "inverted figure of the kingdom" (136). In it, one can witness an attempt at reunification, the production of a body politic that is "at once political and mystical," a recasting of sovereignty as the sovereignty of the people, of the assembly, and no longer of the king: "the nation comes to occupy a very singular place in the 'theologico-political' apparatus of which we are trying to write the history. Constituted as what assembles itself (as what brings about the common, the being of what is in common), it occupies precisely the place of the church, if one is willing to recall that the church is nothing else than the transposed name of the assembly as such" (I43). What is perhaps one of the most forceful illustrations of secularization - the French Revolution as the detheologization of politics - however, fails to erase the division, the constitutive theologico-political structure of politics. In "the Jewish Question," Marx made that failure limpid in terms that remain relevant to this day. "The nation," writes Guénoun, "is a theological idea" (156).

But earlier in the book, Guénoun adds another "axiom" to those we have been exploring. "Europe," he writes, "figures itself facing Islam" (62). Europe gives itself a face, a figure, by way of Islam. Europe fabricates for itself a site where it will be able to protect itself from itself, protect itself from what it projects and imagines as and at its end, the end of Europe. This is to say that, for Europe, Europe and Islam are intimately involved in a "specular formation of mirror images" that is "the primordial identitarian rapport, constitutive of Europeanness" (63). This rapport, an originary structure of Europe, has been very much studied from a variety of perspectives, and we will return to it in the chapters that follow. ${ }^{18}$ What Guénoun here emphasizes and interrogates, even if briefly, is the way in which Islam is historically constituted as exteriority, that is to say, exteriorized. ("At bottom, what we would have to say is this: Islam is not extraneous to our history. Or it is so in a singular fashion: from the inside," 287.) Islam would thus be the becoming-exterior of what is within "our" world- "we, 
Europeans." ("The exteriority of Islam marks its proximity. Islam in our history is the name of this exteriority rising on the internal edge of our world, rushing in and within it," 288.) Nowhere is this clearer, perhaps, than in the modern construction of Islam as "religious fanaticism," which coincides historically with what is still called "secularization." Islam thus becomes an "internal exteriority," an included exclusion, according to the structure of the exception formalized most famously by Carl Schmitt and that will occupy us throughout what follows: If the name of this exclusion, this exteriorization, is "Islam," then in naming itself as what faces Islam, "Europe" hides itself from itself by claiming to have a name and a face independently of Islam. This self-constitution is not only fundamentally related to the question of "religion" in its divisions. It carries with it in unavoidable ways the division between Judaism and Islam, the distinction of Jew from Arab.

Except for a quickly vanishing autobiographical moment, however, Guénoun never links the two figures of Arab and Jew to each other vis-àvis Europe. Thus, under the isolated figure of an excluded inclusion, he leaves Islam aside in order to attend to the "Jewish contribution" to Europe, never explicitly addressing the historical link of Judaism to the figure of Islam and of Islam to the figure of Judaism, within and without Europe. And yet, it is the figure of the "Arabized Jews" (as Guénoun describes his own genealogy) and the Arabic language spoken by his Jewish ancestors that raise more than a historical question regarding the conditions of Guénoun's own writing, of his "hypotheses on Europe." If, according to his acute analyses, Islam is the "external enemy" (that is, if it has become such-becoming enemy as well as becoming external), and Judaism is the "internal enemy," the question that remains, covert and untreated, is indeed the question of a relation, the relation between Europe and the Jew, the Arab. This question would be "more radical," articulating itself, as we will see, around "a reflection upon the constitution of the political out of a religious division" (II7 n. 33). It is both a philosophical and an empirical question, and it constitutes itself as the unwritten history of the theologico-political, a history of the enemy. 
The Enemy, the Jew, the Arab

\begin{abstract}
He who, for example, laughs at the racist joke ... won't have assented to a thesis, which, in this register was not even enunciated, but he will have recognized the essential, which follows no argument and is oblivious to any: that the Jews or the Arabs ... are the index of a major risk, the destruction of all present.

-Alain David, Racisme et antisémitisme
\end{abstract}

A note on terminology. First, as I attempted to access various and no doubt limited, not to say insufficient pathways that would assist and lead me toward accounts of the term "enemy" within the discourse of philosophy, political philosophy, and political science, I was surprised to find only rare and occasional, quantitatively limited discussions. I had to confront, then, something like the disappearance of the enemy, its having vanished from philosophical and political reflections almost from the start, rather than in modern times, as Carl Schmitt argues. ${ }^{19}$ To the extent that one could subsume the question of the enemy under that of war, one would have to acknowledge that the modern discourse on war identified by Michel Foucault and others is always articulated as historico-political (in a narrow sense of these terms), no longer as philosophico-juridical. The claim to "decipher the permanence of war in society" was thus never simply a philosophical claim. ${ }^{20}$ Nor does it engage the fundamental difference between war and the enemy, the excess of the question of the enemy in relation to war. ${ }^{21}$

To the extent that this question - the question of the enemy-does, on occasion, emerge, it does so mainly as an institutional issue, made to attend to modes of behavior ("How to treat the enemy"), or modes of engagement ("How to fight, vanquish, or annihilate the enemy"), and finally, to modes of appearance ("faces of the enemy") and identification ("Who is the enemy?"). The question of ontology_-What is the enemy?"- hardly surfaces, and when it does, as we will briefly consider in Chapter 3 ("De inimicitia"), it is only too quickly rendered almost ephemeral and a testimony to the vanishing, the drawing away of the enemy.

A cursory reading of Western philosophical and political reflections (what is called today political science and/or political theory, as well as political philosophy) quickly reveals that, over against the friend or the beloved, love or friendship (which have been claimed by the expert discourses of philosophy and politics, but also of ethics, psychology, and oth- 
ers), "the enemy" never becomes a basic concept, barely even a significant operative term..$^{22}$ Reasons for the discursive operations of the enemy, the generalization and simultaneous lack of conceptualization of the enemy, may be found in philosophy ("philosophy, when thinking about war, does nothing else than think about peace. It mistakes its objects. ... Thus, the discourse of peace becomes, at the philosophical level, the departure point of the discourse of war. It becomes the founding underground of political philosophy in general."), ${ }^{23}$ or they may be found in political reflections that do engage war, but not the enemy, or, alternatively, that address (and even seem to answer) but fail to ask the question of the enemy. ${ }^{24}$

At any rate, reasons for the state of affairs exemplified here (the state of the question of the enemy) may be numerous, and it remains difficult, if not impossible, to sustain a claim aiming to establish a continuity of the enemy, of the concept of enemy, much less to argue for or demonstrate epistemic shifts or ruptures, strategic developments or secularizing mutations, in the history of the enemy. ${ }^{25}$ More importantly, it remains unclear to what extent the very term "enemy," in the various languages in which it is made to appear here (English, German, French, for the most part, and to some extent, Greek, and Latin) could ever be justified by some alleged semantic identity.

What may be no more than philological vagueness, and even a lack of philosophical rigor, remains dictated, perhaps even governed, by a vanishing, the insistence of a drawing away (which is not quite the absence) of the enemy from any, privileged, discursive sphere. Is the question of the enemy a philosophical, legal, or psychological question? Is it a culturally contained, even a historical and (finally?) a political one? Aside from Carl Schmitt's attempt not so much to revive as to virtually establish the concept of the enemy and to locate the decision concerning the distinction between friend and enemy as the condition of the political, aside from Jacques Derrida's groundbreaking reflections on the enemy in Politics of Friendship, there is very little to authorize or even enable the claim that one could ever write a history of the enemy. ${ }^{26}$ Thus, again, the enemy draws away, leaving behind the question "Why?" and perhaps also, "How?"

According to what protocols, then, and in what modalities, has a history of the enemy become impossible? This book will try to show that this historical impossibility is contingent upon the condition of religion and politics in "Europe," a condition that Derrida has elaborated in his writings on the Abrahamic. ${ }^{27}$ Nothing authorizes the collapse of religious (and 
historically dubious) markers such as Judaism and Islam with ethnic or political markers such as Arab and Jew. Yet already the dissymmetries inherent to the terms ("Jew" and "Muslim," "Jew" and "Arab") are carried by the history that seeks to account for their sedimentation as polarized identities. What appeared to be a lexical choice was not, therefore, ever quite one (even if the use of the term "Arab," with its emphasis on a linguistic dimension, makes it paradoxically more difficult to simply oppose it to "Jew," a term whose religious history or inflection remains slightly more visible). To have followed a restricted tradition that speaks so obscurely, if also so strangely, of a "Judeo-Muslim symbiosis" (away-always far away-from Europe, as if the latter had nothing to do with the former), would already have been to decide to locate the issue in the sphere of religion, however broadly defined. It would have been to ignore that aside from more or less limited syncretistic areas, the two "religions"-if that is what they are-as two bodies of law (Hebrew: dat, Arabic: din), must remain distinct, or at least must claim to remain so for purposes of safety or, as one says, for security reasons. It is by now banal, if also not entirely adequate, to single out and contrast the example of Arab Christians who (aside from, and in excess of, religious differences) constitute well-recognized groups that are, in a variety of ways that differ from one area to another, both distinct and not distinct from the Arab Muslim populations and linked in a manner for which no "Christian-Muslim symbiosis" could ever account. "The Jew, the Arab," then, because things are complicated, multilayered, and many tools of analysis are required to account for terminological possibilities and impossibilities. ${ }^{28}$

But there is another reason to invoke "the Jew, the Arab" in the wide range of historical contexts to which this book appeals. This is a historical reason: that "Europe," which can be said to have long confused the terms, to have collapsed Arab and Muslim, Orientals and Semites, Turks and Saracens, and continues to do so to this day, Europe provides here the site, uncertain and fragmented as it is, from which the two figures emerge as enemies. Enemies of Europe and enemies of each other, "the Jew," "the Arab" are undoubtedly arbitrary names. Yet, they are also old names that have strategically and insistently inscribed themselves with an as of yet unaccounted-for necessity in the history-a history of the present if there ever was one-of Europe and of the West. "The Jew, the Arab," then. And - as if it were possible - a history of the enemy. 

THE JEW, THE ARAB 
